\title{
Construção de Salmonella sorovar Enteritidis Atenuada para Imunização de Mamíferos
}

\section{Ronnie F.M. Sousa*, Marcelo Brocchi}

\section{Resumo}

Salmonella enterica é uma bactéria patogênica para diversos animais, causando infecções intestinais e extra-intestinais. S. enterica contém genes codificadores de Sistemas de Secreção Tipo Três (SSTTs), essenciais para a capacidade de invasão e sobrevivência intracelular. Muitos genes de SSTT são regulados pela proteína IHF: uma histone-like heterodimérica codificada pelos genes ihfA e ihfB. Com isso, temos como objetivo construir S. Enteritidis $\Delta$ ihfA, $\triangle$ ihfB e $\triangle$ ihf $A \Delta$ ihfB, confirmar que os mutantes são atenuados e avaliar a resposta imunológica em murino com o duplo mutante. Até o momento, os mutantes simples e o duplo mutante foram construídos. Os próximos passos serão a caracterização do duplo mutante, ratificar o potencial atenuante do duplo mutante e testar a sua imunogenicidade.

\section{Palavras-chave:}

IHF; S. enterica; Pathogenicity.

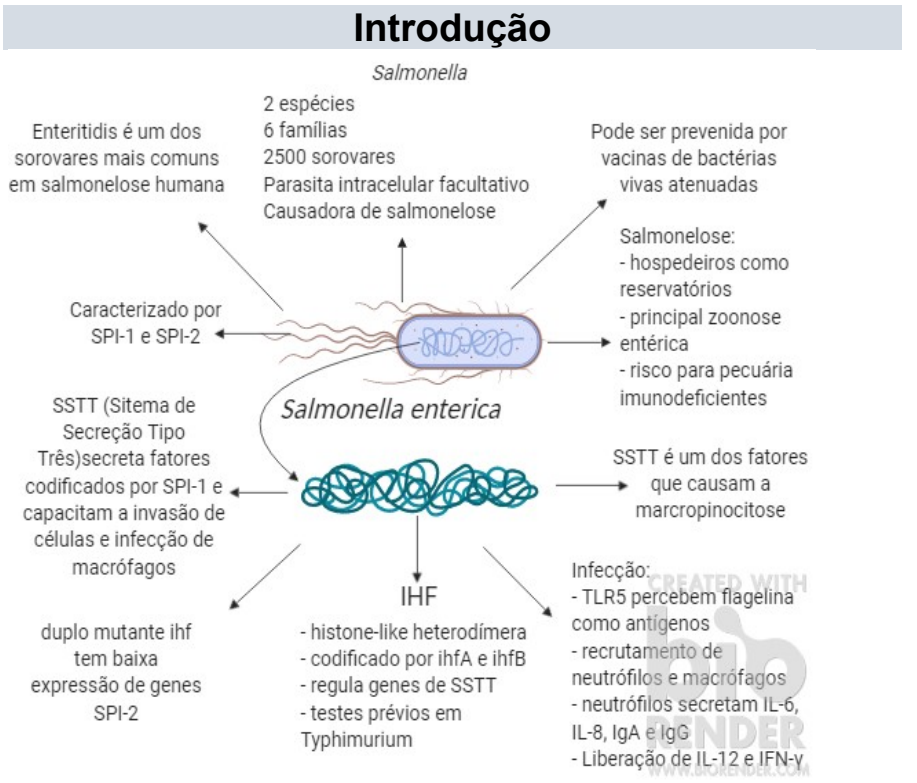

Figura 1. Mapa mental ilustrando as informações essenciais para a compreensão do trabalho.

Com base em resultados preliminares de nosso lab., o presente trabalho tem como objetivo construir linhagens $S$. Enteritidis $\triangle i h f A, S$. Enteritidis $\triangle i h f B$ e $S$. Enteritidis $\triangle$ ihfA $\triangle$ ihfB, confirmar se o duplo mutante é atenuado e capaz de induzir resposta imunológica.

\section{Resultados e Discussão}

A deleção dos genes ihfA e ihfB foi feita pelo sistema $\lambda$ Red utilizando os plasmídeos pKD3, pKD46 e pCP20 Foram isoladas colônias de $S$. Enteritidis $\triangle$ ihfA:Cm e de S. Enteritidis $\triangle i h f B: C m$. Para evitar a seleção de recombinações secundárias, as marcas de deleção foram transferidas por transdução utilizando 0 fago P22Hint (Figura 2A). A resistência ao claranfenicol foi eliminada com o uso do sistema de recombinaçãoo de pCP20 (Figura 2B).

Atualmente estamos retirando as resistências do duplo mutante para prosseguimento nos testes em murinos.
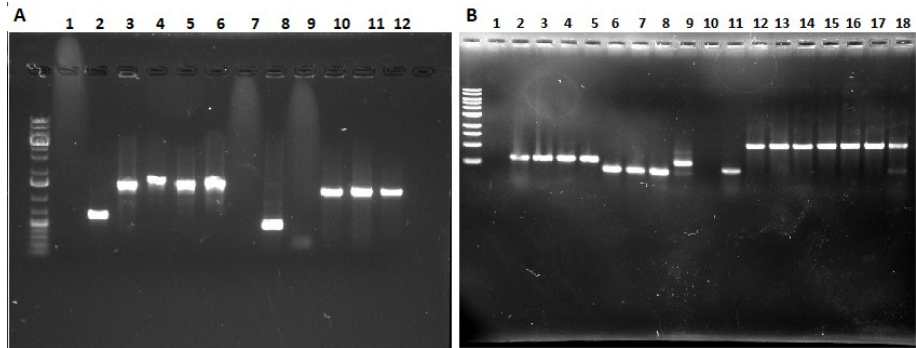

Figura 2. Construção dos mutantes simples (A) e duplo (B). A) Detecção genes íntegros ihfA (2) e ihfB (8) na linhagem selvagem e linhagens $\triangle$ ihfA (3 à 6) e $\triangle i h f B$ (9 à 12). Observa-se que todas as colônias $\triangle$ ihfA apresentaram a deleção, contudo apenas 1 colônia $\Delta$ ihfB apresentou a mutação (amostra 9). B) Detecção dos genes ihfA (amostras 1 à 9 ) e ihfB (amostras 10 à 18) no duplo-mutante por PCR. Temos o controle selvagem do gene ihfA (2) e ihfB (11) e as amostras 3 à 9 são respectivas às 12 à 18 . Observa-se que 3 colônias apresentaram a cicatriz em ihfA $(6,7,8)$ e a deleção do gene $\operatorname{ihfB}(15,16$ e 17).

\section{Conclusões}

Até o momento obtivemos o duplo mutante Salmonella enterica Enteritidis $\triangle i h f A \Delta i h f B: C m$. Esta aparenta ser viável e acreditamos que seu crescimento é igual a linhagem selvagem por dados previamente obtidos pelo nosso grupo. Atualmente, nosso nos empenhamos em retirar as resistências do duplo-mutante para que possamos dar prosseguimento aos testes in vivo.

BRENNER, F.W.; Villar R.G.; Ângulo F.J.; Tauxe R. e Swaminathan B. Salmonella nomeclature. J Clin Microbiol. 2000, 38, 2465

COTTER, P.A. e DIRITA, V.J. Bacterial virulence gene regulation: an evolutionary perspective. Annu Rev Microbiol. 2000, 54, 519.

DATSENKO, K.A. e WANNER, B.L. One-step inactivation of chromosomal genes in Escherichia coli K-12 using PCR products. National Academy of Science. 2000, 97, 6640.

GOOSEN, N. e VAN DE PUTTE, P. The regulation of transcription initiation by integration host factor. Mol Microbiol. 1995, 16, 1.

GUZMAN C.A.; Borsutzky S.; Griot-Wenk M.; Metcalfe I.C.; Pearman J.; Collioud A.; Favre D. e Dietrich G. Vaccines against typhoid fever. Vaccine. 2006, 24, 3804 .

MANGAN, M.W.; Lucchini, S.; Danini V.; Ó Cróinín, T.; Hilton, J.C.D. e Dorman, C.H. Integration Host Factor (IHF) integrates stacionary-phase and virulence gene expression in Salmonella enterica serovar Typhimurium. Mol Microbiol. 2006, 59, 1831. 